\title{
ASPECTOS FITOGEOGRÁFICOS DA BACIA HIDROGRÁFICA DO ARROIO LAJEADO GRANDE, RS - BRASIL. 2 - A VEGETAÇÃO CAMPESTRE ${ }^{1}$
}

\author{
FABIANO DA SILVA ALVES ${ }^{2}$ JOSÉ NEWTON CARDOSO MARCHIORI $^{3}$ \\ LUIS EDUARDO DE SOUZA ROBAINA ${ }^{4}$
}

\begin{abstract}
RESUMO
O estudo fitogeográfico da bacia do arroio Lajeado Grande, oeste do Rio Grande do Sul, levou ao reconhecimento de cinco tipologias de vegetação campestre, intimamente relacionadas ao meio físico: campos em colinas de arenito, campos com butiá-anão em colinas de arenito, campos com curupi em colinas de arenito, campos em colinas vulcânicas e campos com espinilhos em colinas vulcânicas. As áreas de distribuição das mesmas são apresentadas em mapa fitogeográfico anexo.

Palavras-chave: Fitogeografia, Rio Grande do Sul, arroio Lajeado Grande, vegetação campestre.
\end{abstract}

\section{ABSTRACT}

[Phytogeographic features in the basin of Lajeado Grande stream, Rio Grande do Sul state Brazil. 2 - Grassland vegetation].

The phytogeographic studies developed in the hydrographic basin of Lajeado Grande stream, western region of Rio Grande do Sul state (Brazil), allowed the recognition of five types of grassland vegetation, closely related to physical environment: grassland on sandstone hills, grassland with Butia lallemantii (dwarf butia) on sandstone hills, grassland with Sapium haematospermum (curupi) on sandstone hills, grassland on volcanic hills, and grassland with Acacia caven (espinilho) on volcanic hills. The distribution area of these units are presented in a phytogeographic map.

Keywords: Phytogeography, Rio Grande do Sul state (Brazil), Lajeado Grande stream, grassland vegetation.

\section{INTRODUÇÃO}

O oeste do Rio Grande do Sul carece de estudos detalhados sobre a composição florística, distribuição geográfica e vinculações da vegetação natural com o meio físico. Frente esta si-

1 Extraído de "Estudos fitogeográficos na bacia hidrográfica do arroio Lajeado Grande - oeste do RS", Dissertação de Mestrado defendida pelo primeiro autor, em dezembro de 2008, no Programa de Pós-Graduação em Geografia - UFSM. Apoio: FAPERGS - Procorede III - 0614357.

2 Prof., MSc., Universidade da Região da Campanha URCAMP.

3 Prof., Dr., Programa de Pós-Graduação em Engenharia Florestal - UFSM e Bolsista de Produtividade em Pesquisa, $\mathrm{CNPq}$ - Brasil.

4 Prof., Dr., Programa de Pós-Graduação em Geografia UFSM. tuação - e com o interesse de contribuir para o avanço do conhecimento científico, bem como alertar sobre a necessidade de conservação e preservação da biodiversidade e das paisagens naturais no estado -, o presente trabalho tem o objetivo de identificar, caracterizar e mapear as diferentes tipologias de vegetação campestre na bacia hidrográfica do arroio Lajeado Grande, com base em aspectos fisionômicos, florísticos e fitoecológicos.

Localizada no oeste do Rio Grande do Sul, em área dos municípios de Alegrete e Manoel Viana, mais precisamente entre as coordenadas geográficas de $55^{\circ} 20^{\prime} 28^{\prime \prime}$ e $55^{\circ} 36^{\prime} 42^{\prime \prime}$ de longitude oeste, e $29^{\circ} 36^{\prime} 20^{\prime \prime}$ e $29^{\circ} 59^{\prime} 52^{\prime \prime}$ de latitude sul, a bacia do arroio Lajeado Grande (Figura 1) apresenta uma importante diversidade de tipologias em sua vegetação natural. 


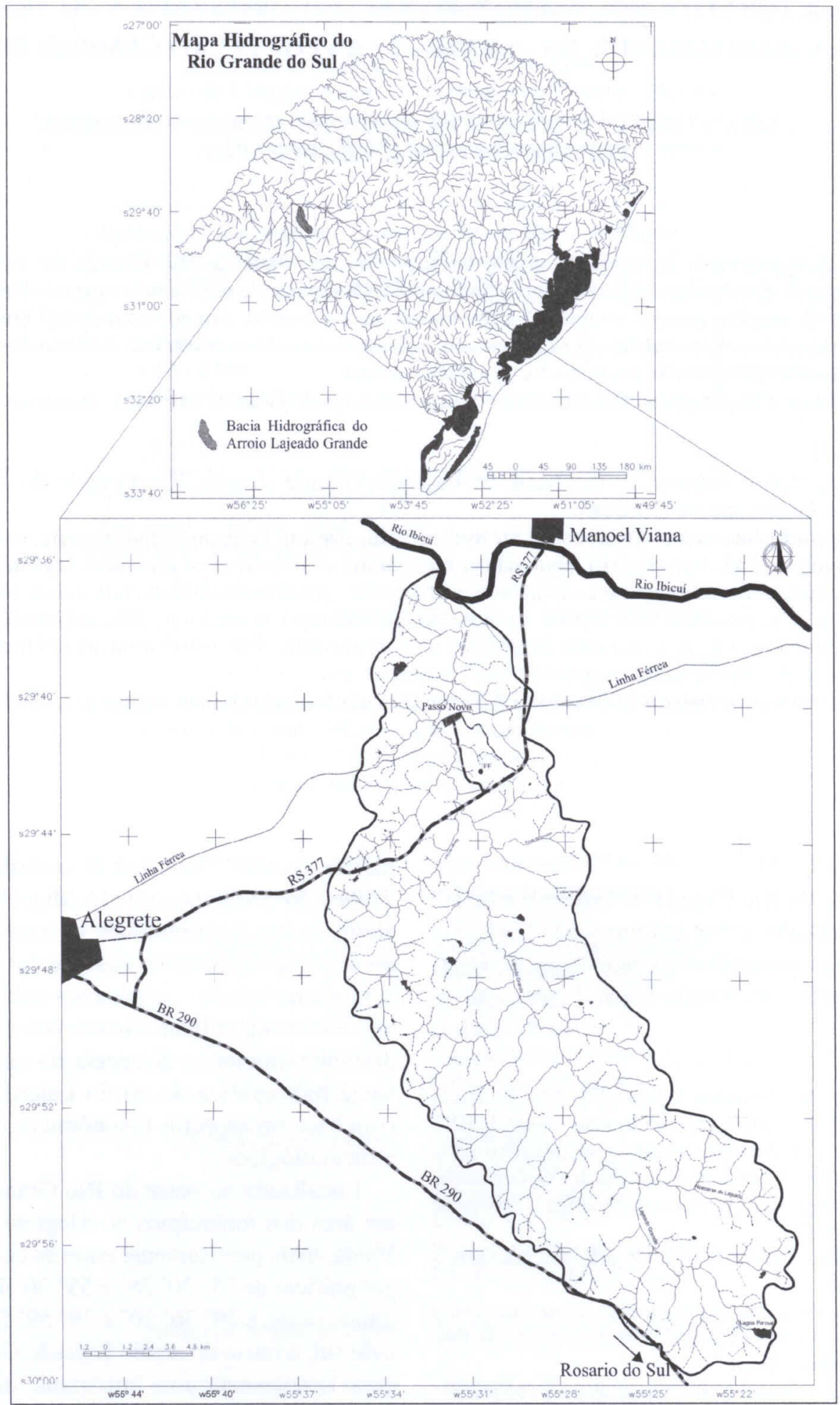

Figura 1 - Mapa de localização da bacia hidrográfica do arroio Lajeado Grande. 


\section{MATERIAIS E MÉTODOS}

Com base no mapa morfolitológico da bacia do arroio Lajeado Grande, apresentado em artigo anterior ${ }^{5}$, em imagens de satélite (ETM Landsat e Google Earth) e em observações in loco, o estudo da vegetação campestre visou definir e mapear, inicialmente, as áreas de ocorrência natural das diferentes tipologias, com base em aspectos fisionômicos.

Na sequência, foram realizados levantamentos florísticos detalhados, em áreas com baixos índices de alteração antrópica. Nesta etapa, utilizou-se uma ficha de inventário fitogeográfico baseada no modelo proposto por Bertrand (1966), constante em Passos (2003). Além de informações gerais (local, data e pesquisadores), foram anotados aspectos relativos à fisionomia da vegetação na área amostral (campestre e/ou arbóreo-arbustiva), a localização geográfica (coordenadas), a identificação botânica das distintas espécies (nome científico, família e hábito), além de aspectos do meio físico (recursos hídricos, relevo, solos, etc.). A identificação das espécies vegetais, realizada inicialmente a campo, teve a amostragem encerrada, em cada tipologia, com base na curva do coletor. Para espécies não passíveis de identificação a campo, coletou-se material vegetativo e/ou reprodutivo para posterior análise em laboratório, com o auxílio de bibliografia especializada e chaves de identificação.

O levantamento de informações do meio físico possibilitou a realização de uma análise fitoecológica, permitindo que as distintas tipologias campestres, definidas, inicialmente, sob os pontos de vista fisionômico e florístico, também fossem caracterizadas com base nos habitats de ocorrência, bem como georreferenciadas e sobrepostas ao mapa morfolitológico. A sobreposição cartográfica destas in-

\footnotetext{
ALVES, F. da S.; ROBAINA, L.E. de S.; MARCHIORI, J. N.C. Aspectos fitogeográficos da bacia hidrográfica do arroio Lajeado Grande, RS - Brasil. 1 - O meio físico. Balduinia, Santa Maria, n. 18, p. 1-9, 2009.
}

formações levou ao reconhecimento preciso de diferentes tipologias de vegetação campestre, bem como de seus respectivos habitats preferenciais.

A caracterização e mapeamento destas unidades, somadas à base cartográfica do mapa morfolitológico, possibilitou, com a utilização dos softwares GTM PRO versão 4.6 (SIG) e Corel Draw X3 (edição gráfica), a elaboração do mapa fitogeográfico da bacia do arroio Lajeado Grande, que inclui as áreas de ocorrência das diferentes tipologias naturais de vegetação campestre, objeto do presente trabalho.

\section{DESCRIÇÃO DAS TIPOLOGIAS}

Apesar das marcas evidentes da ação antrópica em grande parte da bacia, o reconhecimento de tipologias de vegetação tornou-se possível graças à análise integrada de aspectos fisionômicos, florísticos e fitoecológicos. A distribuição geográfica destas unidades é apresentada na Figura 2.

Os campos ${ }^{6}$ nativos, principal tipo de vegetação na bacia do Lajeado Grande, ocupa cerca de $80 \%$ da área total, compondo um tapete gramíneo-herbáceo rasteiro, associado principalmente a colinas de substrato arenítico e vulcânico, bem como a parte dos morrotes e da planície de acumulação. Apesar de sua aparente homogeneidade fisionômica, tais campos apresentam diferenças florísticas e fitoecológicas marcantes, permitindo o reconhecimento de dois grupos principais: campos em colinas de arenito e campos de colinas vulcânicas.

Cabe observar que tais formações nunca são completamente puras, devido, principalmente, à presença abundante de fanerófitas . Representadas por subarbustos, arbustos, arvoretas, árvores, lianas e suculentas, na maioria das vezes organizadas em associações complexas, as

${ }^{6}$ Lindman (1906) esclarece que este termo, de origem indígena, é usado pelo americano do sul (Rio Grande do Sul, Argentina e Uruguai) para caracterizar qualquer território sem mata, independentemente do terreno ou da vegetação. 


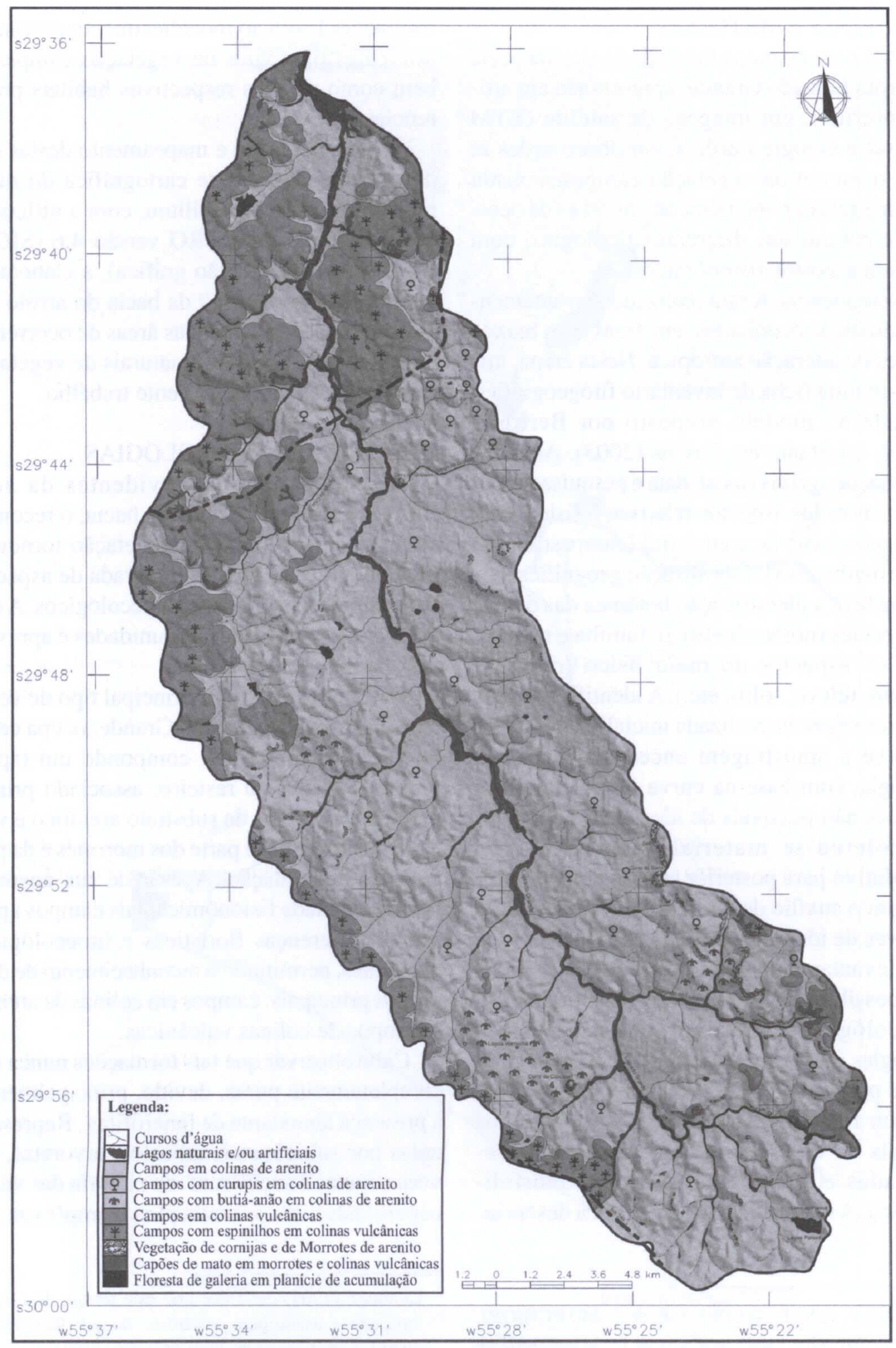

Figura 2 - Mapa fitogeográfico da bacia do arroio Lajeado Grande. 


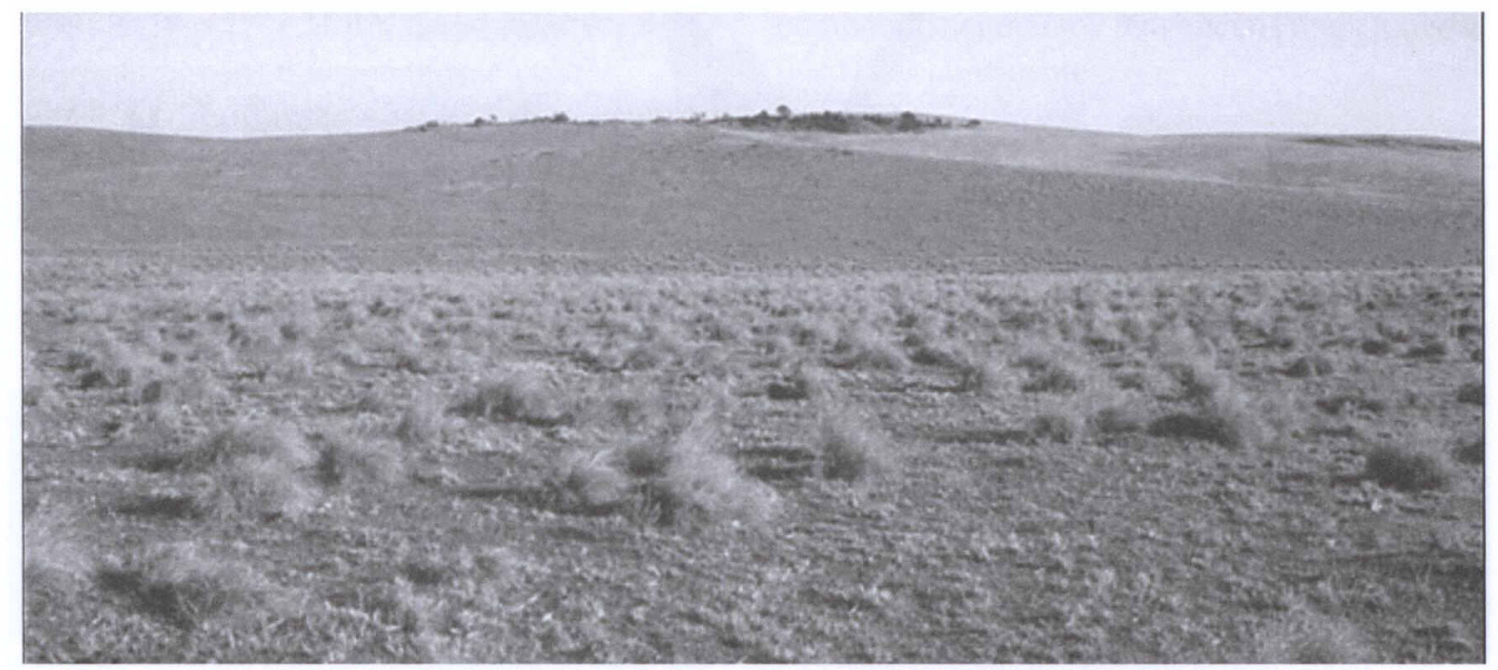

Figura 3 - Aspecto fisionômico dos campos em colinas de arenito: estrato herbáceo baixo e ralo, com presença de gramíneas cespitosas do gênero Aristida (2008).

fanerófitas são as principais responsáveis pela diferenciação de tipologias na vegetação campestre.

Em meio aos campos, por sua vez, não são raras as árvores solitárias; a presença das mesmas, todavia, não resulta suficiente para a segregação de tipologias. Destas pioneiras heliófilas, salientam-se: o umbu (Phytolacca dioica L.), a coronilha (Scutia buxifolia Reissek), o molho (Schinus polygamus (Cav.) Cabrera), o molho-rasteiro (Schinus engleri F.A. Barkley), a taleira (Celtis iguanea (Jacq.) Sarg.) e o sucará (Xylosma tweediana (Clos.) Eichler).

\section{Campos em colinas de arenito}

Formação campestre mais abundante, os campos em colinas de arenito cobrem cerca de $70 \%$ da área total da bacia. A tipologia recebe esta denominação por compor um tapete gramíneo-herbáceo rasteiro e contínuo, associado, com predominância absoluta, a colinas de substrato arenítico e a porções da planície de acumulação (Figura 3).

A composição florística, baseada em gramíneas, inclui, entre outras: as barbas-debode (Aristida circinalis Lindman, Aristida filifolia (Arechav.) Herter), a grama-missioneira (Axonopus fissifolius Raddi), o capim-das-pe- dras (Gymnopogon spicatus (Spreng.) Kuntze) e o capim-rabo-de-burro-miúdo (Schizachyrium spicatum (Spreng.) Herter). Associadas a estas, são freqüentes algumas Amarantáceas (Froelichia tomentosa (Mart.) Moq., Pfaffia tuberosa (Spreng.) Hicken), Asteráceas (Gochnatia cordata Less., Lucilia nitens Less., Vernonia saltensis Hieron.), bem como o tremoço (Lupinus albescens Hook. et Arn.), o trevo-azedo (Oxalis eriocarpa DC.), o fruto-deperdiz (Margyricarpus setosus Ruiz et Pavon) e a tuna-bola (Echinocactus muricatus K. Schum.).

Com ampla dispersão e ocorrência abundante, destacam-se, ainda, algumas nanofanerófitas , como as guavirovas-do-campo (Campomanesia aurea Berg, Campomanesia hatschbachii Mattos), as pitangas-do-campo (Eugenia arenosa Mattos, Eugenia pitanga (Berg) Nied.) (Figura 4), os araçás-do-campo (Psidium incanum (Berg) Burret, Psidium luridum (Spreng.) Burret) e o pessegueiro-do-campo (Hexachlamys humilis $\mathrm{O}$. Berg).

De modo muito particular, o conjunto florístico acima relacionado reúne caracteres visivelmente xeromórficos: sistema subterrâneo muito desenvolvido (xilopódio); folhas reduzidas, coriáceas, brilhantes e/ou revestidas por 


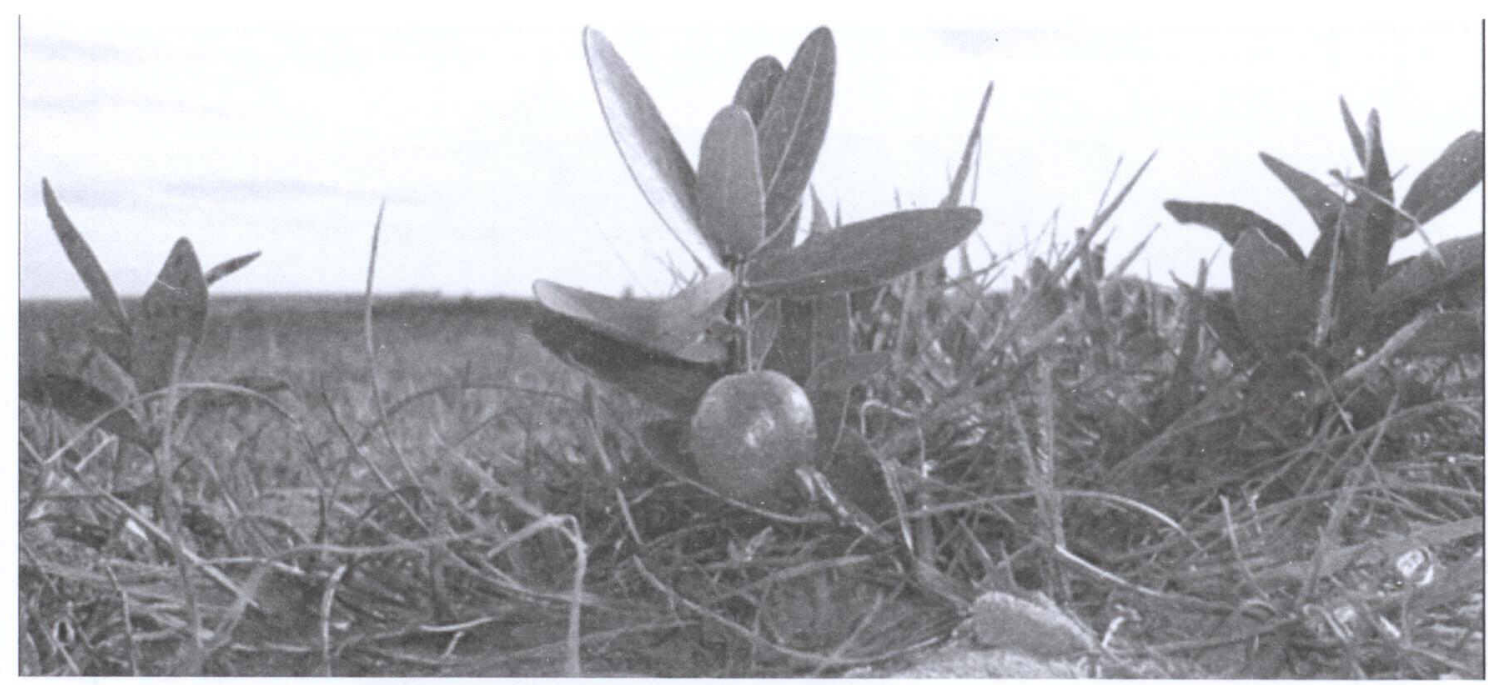

Figura 4 - Pitanga-do-campo (Eugenia pitanga (Berg) Niedenzu), nanofanerófita abundante em campos de colinas de arenito (2008).

indumento; além de tomentosidade acentuada, em órgãos de algumas espécies. De acordo com Marchiori (1995), tais aspectos morfológicos testemunham a ocorrência de fases xerotérmicas no período quaternário e atestam um caráter relitual aos elementos desta flora. Em comple- mento a esta observação, Medeiros et al. (1995) salientam que as colinas de arenito, unidade de paisagem bastante frágil, resultam de paleoambiente semiárido ou semiúmido estepário que, mais recentemente, sofreu umidificação insuficiente para mascarar ou eliminar a influên-

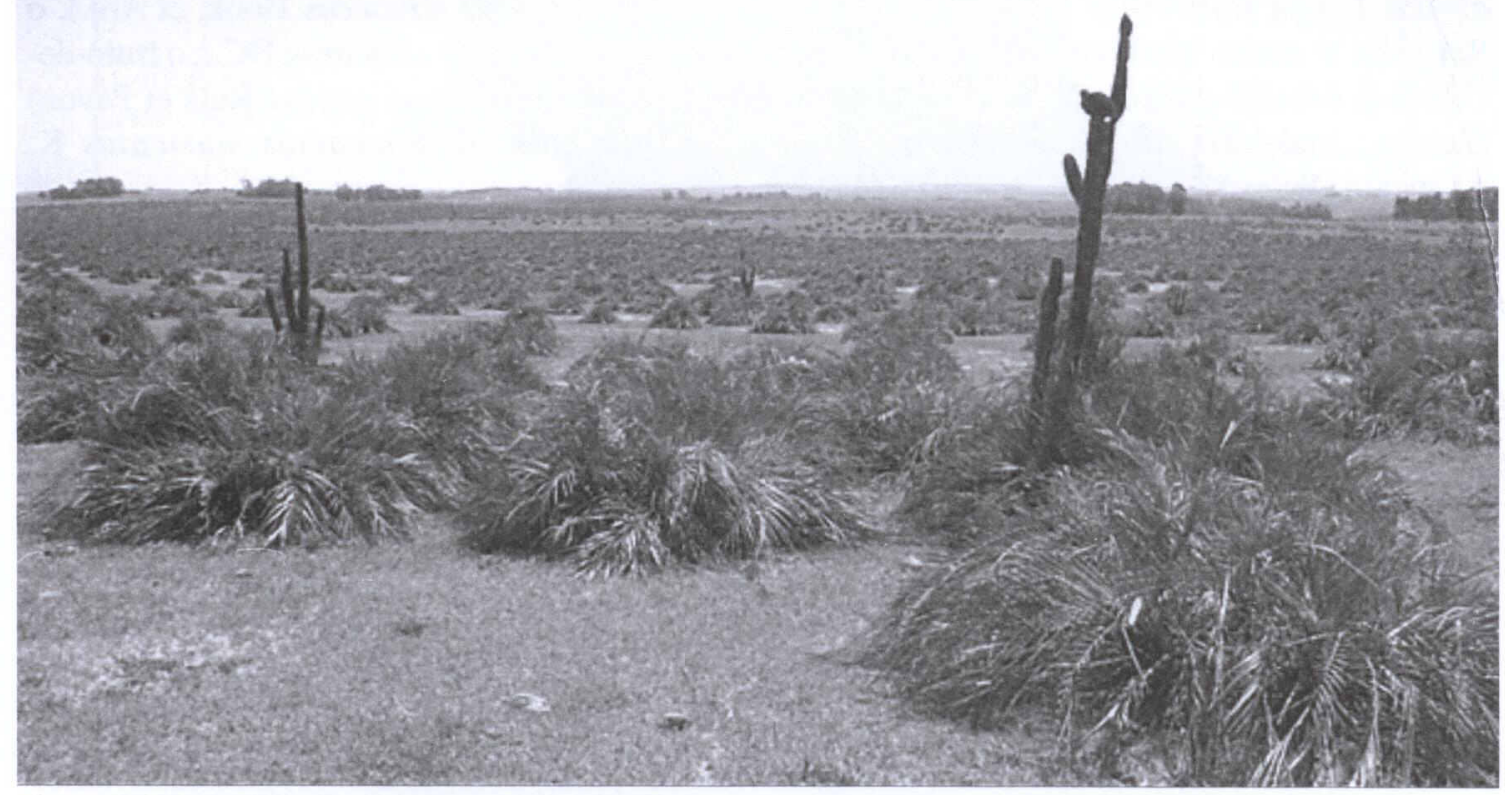

Figura 5 - Palmar de butiá-anão (Butia lallemantii Deble \& Marchiori) com tunas (Cereus hildmannianus K. Schum.), em campo de colinas de arenito (2008). 


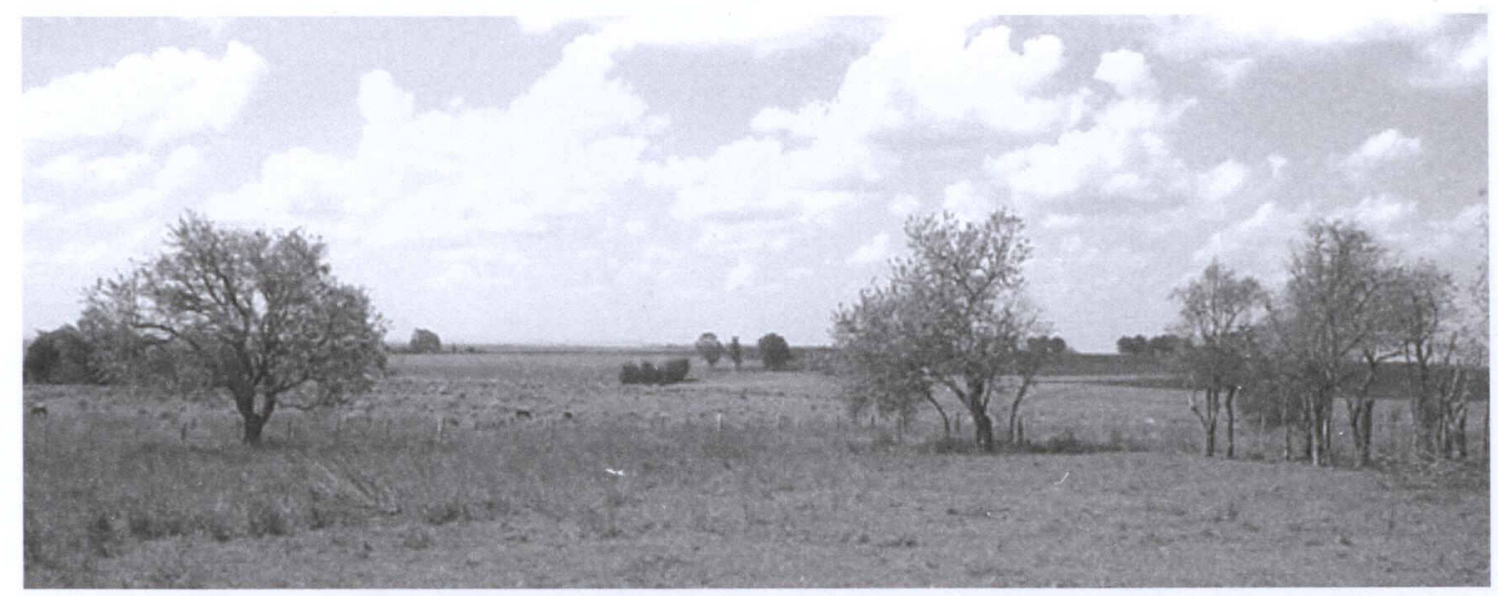

Figura 6 - Curupis (Sapium haematospermum Müll. Arg.), junto a cerca divisória de propriedade rural (2008).

cia do período anterior na paisagem moderna.

Com base no elemento fanerofítico, os campos em colinas de arenito subdividem-se em "campos com butiá-anão" e "campos com curupis".

\section{Campos com butiá-anão em colinas de arenito}

O butiá-anão (Butia lallemantii Deble \& Marchiori), espécie endêmica do oeste e sudoeste gaúcho, tem ocorrência descontínua nas colinas de substrato arenítico, compondo manchas isoladas de poucos hectares que, embora não conectados, chegam a constituir verdadeiros palmares, na maioria dos casos (Figura 5). Nestes campos, além do butiazeiro, não é rara a presença da tuna (Cereus hildmannianus K. Schum.).

Apesar de sua acentuada vinculação a colinas de substrato arenítico, o butiá-anão também ocorre em alguns morrotes de arenito fluvial, como no "Cerro Cascavel", crescendo na vegetação de meia encosta e, até mesmo, no próprio topo, em meio a fendas rochosas.

\section{Campos com curupis em colinas de arenito}

Com ampla distribuição nas colinas de arenito, o curupi (Sapium haematospermum
Müll. Arg.) é mais frequente em áreas de ação antrópica não muito intensa, conferindo à paisagem um aspecto fisionômico de savana. De modo geral, esta fanerófita é mais freqüente em declives suaves de colinas e em morrotes de arenito, vinculada a blocos de rocha, dispersando-se, nos campos, a partir de cercas divisórias de propriedades e potreiros. Nesta situação, também não é rara a presença da tuna (Cereus hildmannianus K. Schum.), cactácea igualmente associada aos campos com curupis (Figura 6).

A correlação entre vegetação e meio físico demonstra que o curupi é espécie "geoindicadora", pois sempre ocorre em campos de solo arenoso, gerado por substrato de rochas areníticas dos tipos fluvial, eólico ou intertrápico.

\section{Campos em colinas vulcânicas}

Tapete gramíneo-herbáceo denso e contínuo, esta tipologia resulta muito distinta, sob os pontos de vista florístico e fitoecológico, dos campos em colinas de arenito. Vinculada, exclusivamente, a colinas vulcânicas e à parte dos morrotes de mesmo substrato, bem como a pequenas porções da planície de acumulação, em pontos favorecidos pela ação antrópica (Figura 7), esta tipologia campestre apresenta, como espécies mais características: a grama-forquilha 


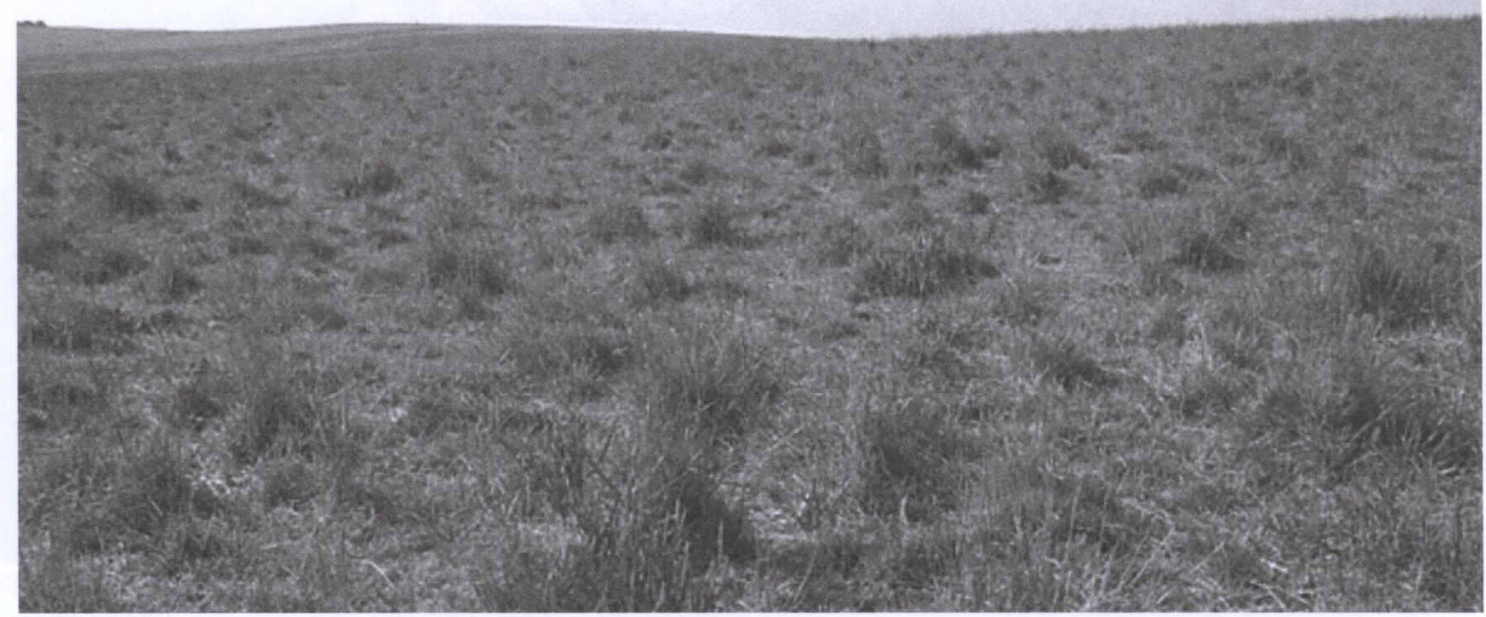

Figura 7 - Tapete gramináceo denso, aspecto característico dos campos em colinas vulcânicas (2008).

(Paspalum notatum Flüegge), o capim-caninha (Andropogon lateralis Nees), o alecrim-do-campo (Vernonia nudiflora Less.), a carqueja-amarga (Baccharis trimera (Less.) DC.), o mio-mio (Baccharis coridifolia DC.), os caraguatás (Eryngium sp.) e, eventualmente, a quina-docampo (Discaria americana Gill. \& Hook.).

Como as colinas vulcânicas estão geralmente estruturadas em camadas rochosas muito delgadas, não é rara a presença de espécies típicas de campos em colinas de arenito nesta tipologia, que assume, por consequência, um caráter misto ou intermediário. Este aspecto torna-se mais evidente em locais onde houve a desintegração e incorporação no solo de camadas vulcânicas pouco espessas, sobrepostas ao arenito; deste modo, é comum a presença de resíduos de rochas vulcânicas no topo, em meio ao solo, ao passo que a base é constituída por arenito eólico ou intertrápico.

A presença do elemento fanerofítico, por sua vez, permite o reconhecimento de uma subunidade: a dos campos com espinilhos.

\section{Campos com espinilhos em colinas vulcânicas}

Espécie comum nos campos de colinas vulcânicas, o espinilho (Acacia caven (Molina)
Molina) distribui-se de modo uniforme, conferindo à paisagem uma fisionomia de SavanaParque (Figura 8).

À semelhança do curupi, esta fanerófita também é "geoindicadora", estando sua presença associada a unidades morfolitológicas com substrato de rochas vulcânicas, com solo rochoso e/ou significativamente argiloso.

\section{CONSIDERAÇÕES FINAIS}

Os estudos fitogeográficos desenvolvidos na bacia do arroio Lajeado Grande levaram ao reconhecimento e caracterização de cinco tipologias de vegetação campestre, com base em aspectos fisionômicos, florísticos e fitoecológicos.

Sob o ponto de vista fisionômico-florístico, salienta-se a importância do elemento fanerofítico, principal responsável pelo aspecto savanóide dos campos. A análise fitoecológica, por sua vez, mostrou que as cinco tipologias reconhecidas estão estreitamente vinculadas ao meio físico, obedecendo a um "padrão" de distribuição geográfica. Certas vinculações mostraram-se tão acentuadas, que duas fanerófitas típicas de formações campestres distintas (Sapium haematospermum Müll. Arg. e Acacia caven (Molina) Molina) foram 


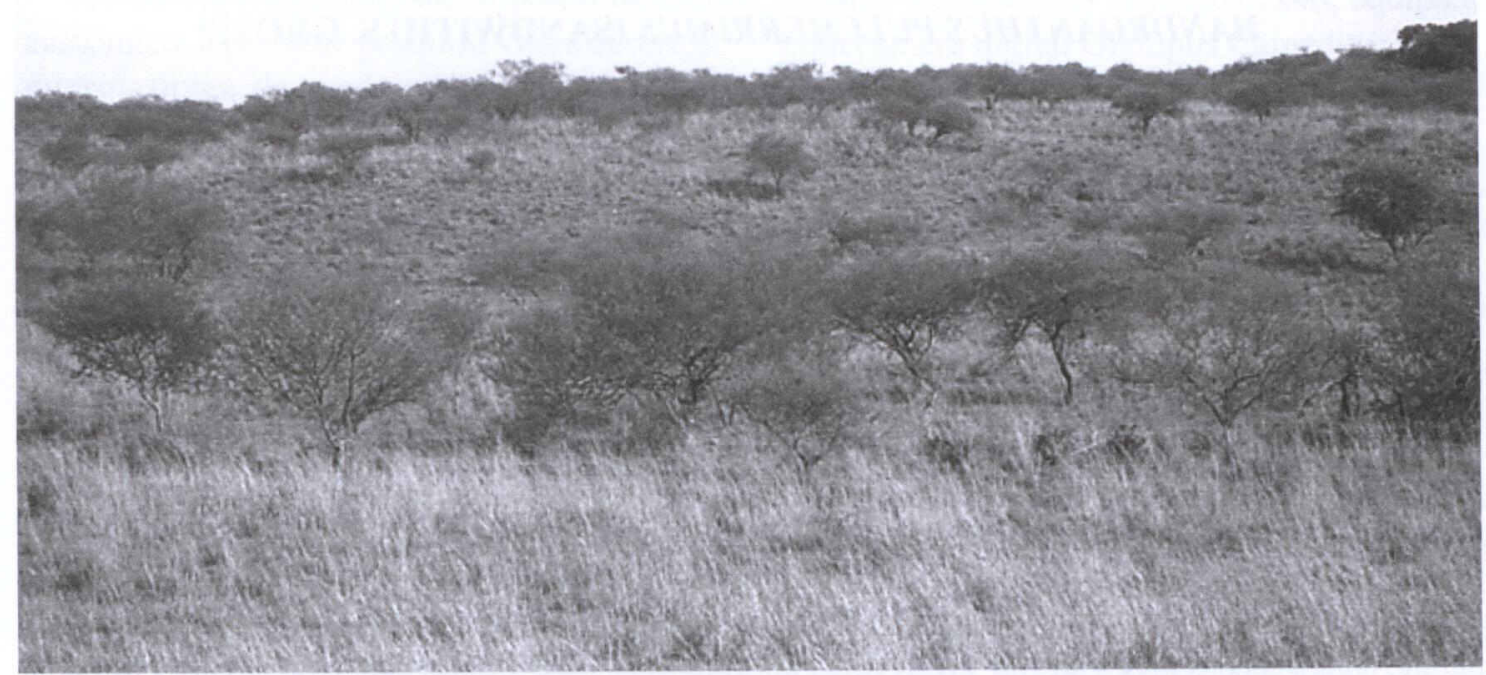

Figura 8 - Espinilhos (Acacia caven (Molina) Molina), em campo de colinas vulcânicas com fisionomia de savana (2008).

reconhecidas como "geoindicadoras" de substrato, por sua seletividade às condições litopedológicas.

Por fim, espera-se que o presente estudo venha a contribuir para o avanço do conhecimento fitogeográfico sul-rio-grandense e, de modo especial, sobre a região oeste do Estado.

\section{REFERÊNCIAS BIBLIOGRÁFICAS}

LINDMAN, C.A.M. A Vegetação no Rio Grande do

Sul. Belo Horizonte: Ed. Itatiaia; São Paulo: Ed. da USP, 1974. 377 p.
MARCHIORI, J.N.C. Vegetação e areais no sudoeste rio-grandense. Ciência e Ambiente, Santa Maria, n. 11, p. 81-92, 1995.

MARCHIORI, J.N.C. Fitogeografia do Rio Grande do Sul: embasamento florístico. Porto Alegre: EST, 2006. 39 p.

MEDEIROS, E. R.; ROBAINA, L.E. de S.; CABRAL, I.L. Degradação ambiental na região centro-oeste do Rio Grande do Sul. Ciência e Natura, Santa Maria, n. 11, p. 53-64, 1995.

PASSOS, M.M. Biogeografia e Paisagem. Maringá, 2003. $264 \mathrm{p}$. 